Review

\title{
COVID-19 Reinfection and its Diagnostic Approach
}

\author{
Ashish William and Ravinder Kaur \\ Department of Microbiology, Lady Hardinge Medical College and Associated Hospitals, India
}

\author{
Article history \\ Received: 26-01-2021 \\ Revised: 02-03-2021 \\ Accepted: 09-03-2021 \\ Corresponding Author: \\ Ashish William \\ Department of Microbiology, \\ Lady Hardinge Medical \\ College and Associated \\ Hospitals, India \\ Email: ashulhmc7@gmail.com
}

\begin{abstract}
COVID-19 caused by Coronavirus strain "Severe Acute Respiratory Syndrome Coronavirus 2 (SARS-COV-2)" has been responsible for the significant threat to the world and its pandemic has become the most important matter of concern in health care systems. The cases of reinfection with virus have been noted in the patients after the discharge. The lack of reporting of COVID-19 virus in asymptomatic cases of reinfection was observed on basis of various studies. Genetically distinct SARS-CoV-2 rules out persistent viral shedding or reactivation. There is not any protocol for the diagnosis of reinfection on the basis of single specimen, therefore it has been advised to test Paired specimens for the diagnosis of reinfection. To minimize the spread of transmission of virus in India, certain necessary steps of prevention has been taken by Indian Council of Medical Research (ICMR) and The Ministry of Health and Family Welfare (MOHFW), India. For the control of the COVID-19, the surges in awareness along with guidelines have been posed as a part of preventive measure in the country. The protocol for diagnosis of reinfection is needed to combat the problem. This is a review article to study the diagnostic approach and diagnostic criteria of reinfection after few cases were studied so far with Indian Scenario. The whole genome sequencing done in these patients provide valuable evidence for reinfection.
\end{abstract}

Keywords: Reinfection, Center for Disease Control (CDC), Sequencing

\section{Introduction}

There has been detectable antibody level as a part of immune response in infection due to SARS-COV-2 virus but it is not well understood about the possibility of reinfection. The neutralizing antibodies develop in the patients who develop the first episode of COVID-19 infection and the degree of protective immunity against this viral infection has not been studied yet (Ju et al., 2020). According to Center for Disease Control (USA), the word reinfection (of Covid-19) is said, if the individual is reinfected following 90 days from going negative to the Sars-CoV-2 subsequent to testing positive to it.

There are many risk factors which lead to severe COVID-19 disease and mortality of the patient, among which Agedness is considered as primary risk factor. The other factors include hypertension, cancer, cardiovascular disease, chronic kidney disease (Jordan et al., 2020). In a study done in China, it has been observed that despite the absence of marker (indicating replication competent virus in feces) responsible for fecal-oral transmission in fecal swabs, the virus is persistently present in the fecal matter (Xu et al., 2020). It was also reported that though the respiratory samples become negative in COVID 19 patient, fecal samples has been observed to remain positive for the next 33 days (Chen et al., 2020). Therefore it was proved that the viral replication is different in the respiratory tract and gastrointestinal system. Even after the viral load becoming empty in the respiratory tract, the viral replication may occur in the gastrointestinal tract.

The high levels of transmission leading to COVID-19 has been noticed due to the gatherings in eating outlets, passenger ships, pubs and certain places of work including healthcare facilities (Hung et al., 2020). Even though adequate strict preventive steps have been taken, there has been exponential rise in the cases of virus in most of the place worldwide. The comeback of the virus has also been observed in the areas where there is lag in the maintenance of social distancing among people (To et al., 2020a).

Richard L Tillett and his colleagues have notified the first confirmed case of reinfection by COVID-19 virus in USA. The case was of a young male, 25 year old patient with no immunological disorder. He belong to US state of Nevada. He came positive by PCR on April, 2020 with $\mathrm{Ct}$ value of $35 \cdot 24$. The patient was kept in quarantine and came negative twice in the tests done at two intervals by RT PCR. The patient was tested again after 48 days of the initial test by PCR and reported positive with $\mathrm{Ct}$ value of 35.31 (Iwasaki, 2021). 


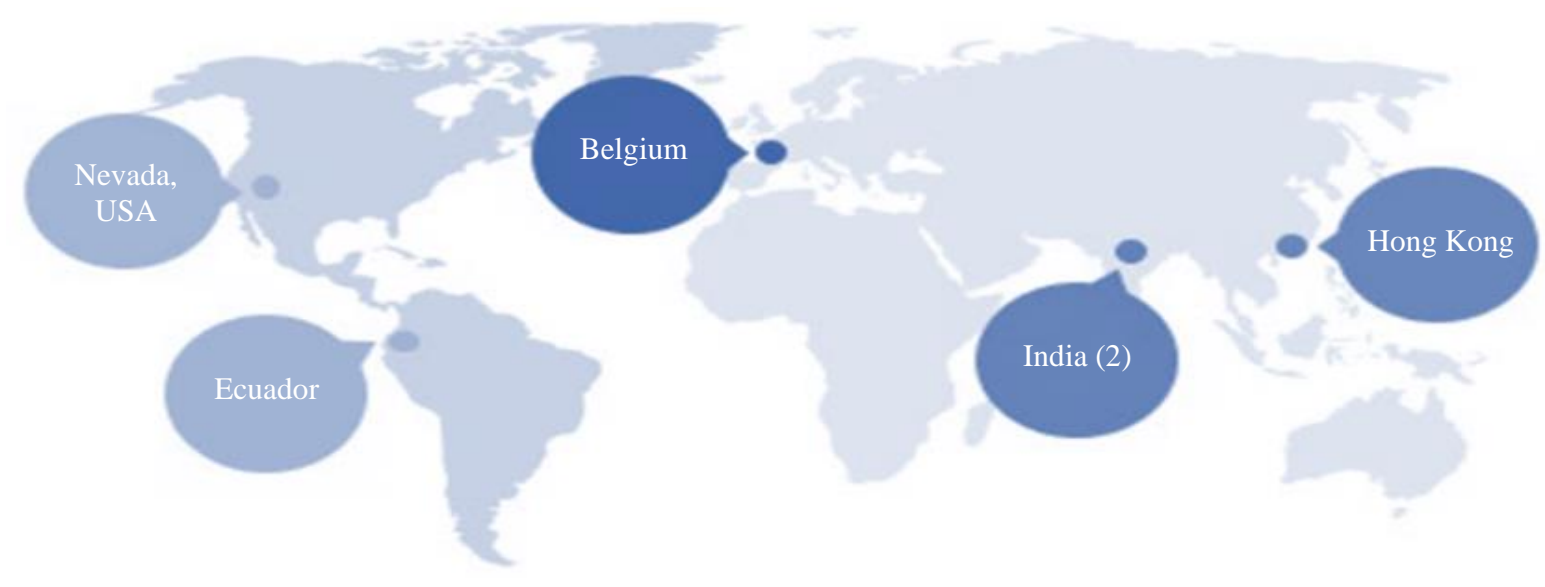

Fig. 1: Location of initial reinfection cases in the world

Table 1: Comparison of initial reinfection cases worldwide

\begin{tabular}{|c|c|c|c|c|c|c|c|}
\hline Location & Gender & $\begin{array}{l}\text { Age } \\
\text { (yrs) }\end{array}$ & $\begin{array}{l}\text { First } \\
\text { infection }\end{array}$ & $\begin{array}{l}\text { Second } \\
\text { infection }\end{array}$ & $\begin{array}{l}\text { Intervening } \\
\text { period (days) }\end{array}$ & $\begin{array}{l}\text { Antibody after } \\
\text { first infection }\end{array}$ & $\begin{array}{l}\text { Antibody after } \\
\text { reinfection }\end{array}$ \\
\hline Hong Kong & Male & 33 & Mild & Asymptomatic & 142 & Negative & IgG positive \\
\hline Belgium & Female & 51 & Mild & Milder & 93 & Data not available & IgG positive \\
\hline Nevada, USA & Male & 25 & Mild & Hospitalised & 48 & $\begin{array}{l}\text { Data not } \\
\text { available }\end{array}$ & $\begin{array}{l}\text { IgM positive, } \\
\text { IgG positive }\end{array}$ \\
\hline Ecuadar & Male & 46 & Mild & Worse & 63 & $\begin{array}{l}\text { IgM positive } \\
\text { IgG positive }\end{array}$ & $\begin{array}{l}\text { IgM positive, } \\
\text { IgG positive }\end{array}$ \\
\hline India & Male & 25 & Asymptomatic & Asymptomatic & 108 & Data not available & Data not available \\
\hline India & Female & 28 & Asymptomatic & Asymptomatic & 111 & Data not available & Data not available \\
\hline
\end{tabular}

The various locations of reinfection cases has been noted as shown in Fig. 1. The most reinfection cases has been asymptomatic along with detection of antibodies as shown in Table 1.

\section{Indian Scenario}

According to WHO data of $11^{\text {th }}$ November 2020, the worldwide prevalence of confirmed COVID-19 positive cases were around 51.4 million confirmed cases of COVID-19 with the overall mortality of around 1.27 million cases. In India the prevalence of confirmed positive cases were seen to be around 8.64 million with mortality of more than around 0.1 million.

In India, there were two cases of reinfection reported by Gupta et al. (2020). These both cases were immunocompetent health care workers who were working in COVID-19 unit in their respective health care institutions. Among both patients, the first patient (Patient 1) is a young male of 25 years old. He was asymptomatic and was tested for COVID-19 by RT-PCR on $5^{\text {th }}$ May 2020 as per routine surveillance of the health institution. He was tested positive with $\mathrm{Ct}$ value of 36 . The patient was put in isolation and was tested negative later by PCR as per institutional policy. The patient started his work and was tested for COVID-19 on $17^{\text {th }}$ August by RTPCR. The result came positive again for
COVID-19 by RTPCR with Ct value of 16.6. He was isolated again and throughout the entire second episode was found to be asymptomatic. For this patient, the testing was not done for Antibody, neutralize antibodies or viral culture. The sequencing was also done for both episodes of the case. In both positive episodes, nine variant differences were observed.

The second patient (Patient 2) is a young female of 28 years old. She was asymptomatic and was tested for COVID-19 by RT-PCR on $17^{\text {th }}$ May 2020 as per routine sureillance of the health institution. She was tested positive with $\mathrm{Ct}$ value of 28.16. The patient was put in isolation and was tested negative later by PCR as per institutional policy. The patient started his work and was tested for COVID -19 on $5^{\text {th }}$ September by RTPCR. The result came positive again for COVID-19 by RTPCR with $\mathrm{Ct}$ value of 16.92. He was isolated again and throughout the entire second episode was found to be asymptomatic. For this patient, the testing was not done for Antibody, neutralize antibodies or viral culture. The sequencing was also done for both episodes of the case. In both positive episodes, ten variant differences were observed.

In this second episode, there is variation in the DNA with nucleotide Thiamine (T) i.e., $22882 \mathrm{~T}>\mathrm{G}$ (SN440K) within the receptor-binding domain as detected in the sample.

The preservation of RNA was done in RNA sequencing libraries after taking consent from the 
patients. The two methods of next generation sequencing (amplicon and capture based) have been used. Illumina MiSeq sequencing though leads to production of paired sequence usually reads till 300 base pairs. RNA sequencing libraries in these two cases were processed on 75 base pairs $\times 2$ paired-end recipe (Grifoni et al., 2020a). The assembly of the genomes is done (around $13684 \mathrm{X}$ ) once the data files in Illumina are blended. The COVID-19 genome (NC_045512.2) used for reference was observed to be partially covering for both episodes. It was seen to be constituting 89.08 and $99.96 \%$, respectively for patient 1 and 85.60 and $92.14 \%$ for patient 2 (Grifoni et al., 2020a). As can be seen from Fig. 2, the genome study had shown 9 and 10 variant differences in the locus of viral genes in both the cases of reinfection (Poojary et al., 2019). The known antigenic determinants was speculated for 7 variants by mapping of both cases of reinfection (Grifoni et al., 2020a).

As can be analyzed from both of the patients (Patient 1 and Patient 2) it is observed that asymptomatic reinfection is underreported. The continuous viral shedding or reactivation is ruled out due to the different genomes of SARS-CoV-2. During reinfection, there is need for continuous surveillance as higher viral load is seen in both individuals. During reinfection, in patient 2 genetic variant 22882T>G (S: N440K) was observed according to which resistance to neutralizing antibodies has been probably there (Weisblum et al., 2020). There has been paucity of the literature regarding genomic information of the COVID-19 virus. The cases in this review gives valuable primary information on the complete genome specification as determined by Next generation sequencing. However in health care systems, there is further requirement of the surveillance for COVID-19 reinfections.

\section{Mechanism of Reinfection}

The mechanism of COVID-19 reinfection is unclear. In reinfection, the immunity provided by both $\mathrm{B}$ cell and $\mathrm{T}$ cell (humoral and cell mediated) are observed to be crucial for its prevention (Chandrashekar et al., 2020). Generally the production of antibody against SARSCoV-2 virus infection can be identified in 2 weeks of infection in patients which usually determines the present/past infection (To et al., 2020b). There is development of neutralizing and nonneutralizing antibodies which is observed between day 10 and day 21 after the COVID-19 viral infection (To et al., 2020a).

In extreme cases of reinfection, there is strong response by neutralizing antibody (>90\%) (Liu et al., 2020). With the decrease of antibodies to virus, the chance of reinfection become higher (Long et al., 2020). Most of the patients develop IgG positivity $(>91 \%)$ on serological tests according to the various data as per various studies (To et al., 2020a).

The information regarding the defense mechanism produced by immunity of B cells or T cells against the
COVID-19 virus is still lacking. The immunity against the COVID-19 virus is determined by the titres of antibody (Ibarrondo et al., 2020). The viral neutralization activity coincide with the antibody levels (anti-receptor domain) due to SARS-COV 2 virus infection (Ibarrondo et al., 2020).

$\mathrm{T}$ cell immunity is expressed by the COVID-19 infection which is seen to be abiding for long time (To et al., 2020a). The glycoprotein present on the surface of COVID-19 virus is the site of attachment of $\mathrm{T}$ cell for the production of immunity against the virus. This glycoprotein is also called spike protein. The helper $\mathrm{T}$ cells and cytotoxic $\mathrm{T}$ cells response can also be observed against the virus as a part of immunity (To et al., 2020a; Le Bert et al., 2020). Grifoni et al., 2020a there are many targets for the helper cells (CD4) which is part of necessary action against the virus. The first target is the structural protein and second target is nonstructural proteins. Spike, membrane, nucleoprotein and nsp4, ORF8 are these targets (structural and nonstructural protein) (Braun et al., 2020). Usually cytotoxic protein is responsible for targeting nonstructural protein of the virus as a part of immunity. These target sites include (nsp6, ORF3a and ORF8) (Grifoni et al. 2020b). Therefore it is evident that the $\mathrm{T}$ cell plays the part for the immunological response along the $\mathrm{B}$ cell antibody production.

\section{Diagnostic Approach}

It has been noticed that there is decline in the level of antibodies (titres) from 1-2 months after the acute infection with the COVID-19 virus (Long et al., 2020). It is seen that there is attainment of less viral load at such a level that patient is usually detected as negative by RT-PCR as detection level is not picked up during result so the patients are usually discharged from the hospitals (Le Bert et al., 2020) and second infection is usually picked up at a later stage as reinfection (Snyder et al., 2020). It has become the hot topic of dilemma to observe the constant viral load after the primary COVID-19 infection as a causative factor for reinfection (Robbiani et al., 2020).

Though the usual symptomatic reinfection patients undergo testing as per the protocol, the diagnosis for the reinfection in those patients without symptoms is most commonly observed during the surveillance done as a routine protocol (Duggan et al., 2020).

The other viral diseases should be kept in mind as a part of differential diagnosis especially during the weather variations like other virus causing respiratory infections, influenza whose symptoms mimic COVID-19 virus clinical picture.

There is variation in viral load distribution according to swabs. As observed in Table 2, there is similarity in Nasal swab and Oropharyngeal swab viral load with time as compared to rectal swab. 
Table 2: Distribution of viral load according to specimens (To et al., 2020c)

\begin{tabular}{llll}
\hline Swab & Start of increase in viral load & Highest viral load detection & Start of decrease in viral load \\
\hline Nasal swab & First day & In first week & After third weeks \\
Oropharyngeal swab & First day & In first week & After third weeks \\
Rectal swab & From the finishing of first week & In second week & From the finishing of third week \\
\hline
\end{tabular}

\begin{tabular}{|c|c|}
\hline \multicolumn{2}{|c|}{$\begin{array}{l}\text { Its episode: SARS COV-2 lab confirmed } \\
\text { infection (symptomatic or asymptomatic) }\end{array}$} \\
\hline \multicolumn{2}{|c|}{ Yes } \\
\hline \multicolumn{2}{|c|}{$\begin{array}{l}\text { 2nd episode: SARS COV-2 laboratory test } \\
\text { (symptomatic or asymptomatic) }\end{array}$} \\
\hline Positive $\downarrow$ & Negative $\downarrow$ \\
\hline $\begin{array}{l}\text { Confirm second positive } \\
\text { test }\end{array}$ & $\begin{array}{l}\text { Reinfection } \\
\text { excluded }\end{array}$ \\
\hline $\begin{array}{l}\text { Whole genome } \\
\text { sequencing data: }\end{array}$ & \\
\hline $\begin{array}{l}\text { Correlates that different } \\
\text { episodes are caused by } \\
\text { different viruses. } \\
\text { Sequences belong to } \\
\text { different clades } \\
\text { irrespective of Single } \\
\text { Nucleotide } \\
\text { Polymorphism (SNV). }\end{array}$ & \\
\hline
\end{tabular}

Fig. 2: Approach to a case in reinfection (Roy, 2020)

The following main criteria which are mentioned below are needed along with clinical assessment of an individual for the diagnosis of true reinfection (Roy, 2020):

1. Confirmation by Laboratory of two different strains for two infections with timely separated illness/infection episodes (Rueca et al., 2020)

2. In diagnosis of those cases with suspected cases for reinfections: There is further more investigations which are required for the diagnosis of reinfection which lead to the final report considering the causative factors of reinfection. The understanding from these investigations is further required to support and guide public health authorities to take appropriate step to combat reinfection. The following information is provided from these investigations (Roy, 2020)

a) Epidemiological information: The information about the probable exposure can be assessed from these investigations

b) Clinical information: In both episode, presence and severity of disease can be seen including the clinical course, detection and recovery time. The correlation of comorbidities and immunotherapy can be correlated with inflammatory markers like C Reactive Protein (CRP) for the diagnosis for the reinfection as there will be corresponding low level of immune response and usually wont show positivity by diagnostic PCR tests c) Testing information/including test result and specimens: The various parameters involved in testing of COVID-19 can be observed for the quality purpose (time of sample received, time of sample testing, date of sample received, date of sample testing, place/health institution of sample testing). The type of Specimen like (e.g., respiratory, saliva) and $\mathrm{Ct}$ values in $\mathrm{RT}$ PCR results for the accurate results in diagnosis is helpful

d) Antibodies information in paired samples: It is provided by Immune assessment tests which provides information regarding duration/persistence along with type and titres of antibodies [range]. Even the titres of neutralizing antibodies level (at day 0,7 and 14) can be observed from primary and reinfection cases as its level coincide with the COVID-19 infections. The biomarkers such as CD40L are also helpful for providing valuable information

e) Detection of growth by cultures: The culture for the growth of virus from multiple specimen types is informative for the diagnosis

f) Information regarding genome by Comparative genomic analyses -it is possible by Whole Genome Sequencing (ECDC, 2020) which detects the Single Nucleotide Variations (SNVs) (helpful in correlation of the causative factor in primary and reinfection episode) (Rueca et al., 2020). The difference in genetic pedigree (ECDC, 2020) or clade (Wang et al., 2020) can be observed as change in sequence of DNA (mutagenesis) is evident in the cases of reinfection

\section{Laboratory Evidence of Reinfection (Rambaut et al., 2020) (CDC)}

According to Centre for Disease Control and prevention (CDC), for further investigations of COVID-19, the division of time period is done as described below:

a) $\geq 90$ days after the primary COVID-19 infection in cases with/without symptoms.

b) b)45-89 days after the primary COVID-19 infection in cases with symptoms

There are various criterias described for reinfection according to time period as shown in Table 3. Some factors need to be taken into consideration while diagnosing a case of reinfection for accurate diagnosis (Table 4). 
Table 3: Criteria including investigations to diagnose reinfections (Rambaut et al., 2020)

\section{Investigation of cases is done that meet criterion A or B \\ a. In cases $\geq 90$ days after the primary COVID-19 infection Paired Nasopharyngeal/Oropharyngeal swabs are taken}

b. In cases 45-90 days after the primary COVID-19 infection If there is no other cause along with symptomatic reinfection case

OR

Laboratory confirmation of positive close contacts

- Paired Nasopharyngeal/Oropharyngeal swabs are taken In the health care set ups with scarcity of genomic testing capacity, CDC has suggested to prioritize investigations in persons with $\geq 90$ day time window as the longer time interval between first and second infection has higher suspicion for reinfection.
2. Decision of laboratory tests to be conducted

Next generation sequencing for investigation of reinfection. It may/may not be enough for Single nucleotide polymorphism analysis for distinguishing reinfection from long-term shedding.

Quality include the genomic coverage (as defined in Next strain or GISAID). The criterias include:

- The significant coverage include $>100$ in one position of base as requirement by agreement generation.

- The agreement with $\mathrm{Q}$ score $>30$ which includes genome coverage $>99 \%$.

- Recommendation of genome coverage of $1000 \mathrm{x}$ for minor variation.

- Recommendation of removal of contaminant (DNA product as amplicon)

Additional points include:

- The substitute of sequencing tests is recommended in case of low accuracy for sequencing tests. (Q score $<30$

Table 4: Factors to be assessed for second COVID 19 infection (Roy, 2020)

\section{RT PCR False}

positivity result

Time period for serological diagnosis

Infectious virus identification

Sequence/ phylogenetic analysis

Though the likelihood for false positive COVID-19 test is rare, it should be examined with high precision. The predictive values depend on the prevalence of COVID-19 virus in various areas (prevalence is directly propotional to the predictive value of SARS COV-2 virus). The contamination level can be the reason for the result of false positivity. Even technical errors can provide false results by RT PCR

The serological analyses at various points of time of reinfection after the first COVID-19 infection provides necessary details (when considering a potential reinfection). The chances of reinfection develops once there is decrease in the immunity due to the drop in the titre of antibody. As there is less duration between confirmatory negative and positive PCR test, it is more likely for the possibility of redetection of the primary episode than a true reinfection

Surprisingly the positivity of the RTPCR test remains same though the viability of viral nucleic acid is not there. This is due to the persistence of the infection due to the remnants of the nucleic acid which is present in the sample

After the primary infection, there are investigations which can differentiate viable virus presence from non viable virus

The test includes Virus culture which is helpful for this purpose as it provides the valuable information as required regarding viability

Negativity of culture indicates the non viability of the virus which is positive viceversa and confirmed by PCR (viral load for quantification) and genome sequencing for the strain variants

The identification of different virus variant in reinfection cases is assessed by Whole genome sequencing of the virus

As there is mutagenesis in COVID-19 virus within the host, the careful assessment is needed to evaluate Sequence/phylogenetic differences during reinfection. There is also possibility of double infections by different strains of COVID-19 virus

There are various magnitude of evidences for the evaluation of diagnosis for reinfection by COVID-19 which are as follows.

\section{Best Evidence}

Identification of different clades as defined in Nextstrain and GISAID of SARS-CoV-2 between episodes of first and second infection, which is actually coupled with other evidence of COVID-19 infection (e.g., high viral titres in each sample or positive for sgRNA and culture).

\section{Moderate Evidence}

It includes $>2$ nucleotide differences per month ${ }^{*}$ in consensus between sequences that meet quality metrics above, ideally coupled with other evidence of actual infection (e.g., high viral titres in each sample or positive for sgmRNA and culture).

\section{Poor Evidence but Possible}

It includes variation in $<=2$ nucleotide per month ${ }^{*}$ in consensus between sequences that meet quality metrics above or variation in >2 nucleotide per month* in 
consensus between sequences that do not meet quality metrics above, ideally coupled with other evidence of actual infection (e.g., high viral titres in each sample or positive for sgmRNA and culture):

- The estimation of rate of mutagenesis in COVID-19 reinfection is observed by atleast 2 nucleotide differences in one month which is $>6$ difference in nucleotide if reinfection case is > 90 days post primary COVID-19 infection.

There is not any rule which has been made for the diagnosis of reinfection on the basis of single specimen, therefore it has been advised to test Paired specimens for the diagnosis of reinfection (Rueca et al., 2020). The culture or sub-genomic mRNA analysis or serology is helpful in providing supporting evidence of reinfection which is not definitive but could be helpful for the serologic response to SARS- COV-2. The clinical course and data on epidemiologic studies provide other evidence of reinfection besides laboratory evidence (Rambaut et al., 2020).

\section{Conclusion}

The more data is needed for the deciding the duration of antibody levels for immunity as well correlation of antibodies with the shedding of virus to provide evidence of reinfection. The Immunological studies are needed for various episodes, to provide information about the various parameters involved in determining the case of reinfection. This information is useful as severity in case of recent reinfection case has been observed more than the first infection (Tillett et al., 2021). The protective antibody titre is also noticed by studying the reinfection case which is seen as an important parameter required for vaccine trials.

The classification of reinfections is needed for a case definition according to standardized laboratory investigations. The surveillance is also required regarding the collection of data on reinfections. There is need for many parameters which are required to diagnose the reinfections for confirmation as needed for the epidemiological purpose. Clinical and laboratory investigations standardization is supported with laboratory procedures and case definitions as a part of investigation protocol.

The accurate constant follow up along with the data of the patient is necessary for the proper management. In case of the persons who are close contact, various protocols including the investigations are needed to diagnose and further manage in case of reinfection confirmation.

\section{Acknowledgment}

I would like to thank Dr. Ravinder Kaur (Director Professor \& Head of Department, Microbiology)for constant support and motivation for helping in the completion of the article.

\section{Author's Contributions}

Ashish William: Organised and drafted the manuscript.

Ravinder Kaur: Supervised and edited the language and has provided valuable additions in the content and structure of the manuscript for final submission.

\section{Ethics}

This review article has been thoroughly read by the authors and has confirmed that there are no ethical issues involved.

\section{References}

Braun, J., Loyal, L., Frentsch, M., Wendisch, D., Georg, P., Kurth, F., ... \& Thiel, A. (2020). SARS-CoV-2reactive $\mathrm{T}$ cells in healthy donors and patients with COVID-19. Nature, 587(7833), 270-274. https://doi.org/10.1038/s41586-020-2598-9

Chandrashekar, A., Liu, J., Martinot, A. J., McMahan, K., Mercado, N. B., Peter, L., ... \& Barouch, D. H. (2020). SARS-CoV-2 infection protects against rechallenge in rhesus macaques. Science, 369(6505), 812-817. https://doi.org/10.1126/science.abc4776

Chen, Y., Chen, L., Deng, Q., Zhang, G., Wu, K., Ni, L., .. \& Cheng, Z. (2020). The presence of SARS-CoV-2 RNA in the feces of COVID-19 patients. Journal of Medical Virology, 92(7), 833-840. https://doi.org/10.1002/jmv.25825

Duggan, N. M., Ludy, S. M., Shannon, B. C., Reisner, A. T., \& Wilcox, S. R. (2020). A case report of possible novel coronavirus 2019 reinfection. The American Journal of Emergency Medicine. https://doi.org/10.1016/j.ajem.2020.06.079

ECDC. (2020). Reinfection with SARS-CoV-2: Considerations for public health response. European Centre for Disease Prevention and Control.

Grifoni, A., Sidney, J., Zhang, Y., Scheuermann, R. H., Peters, B., \& Sette, A. (2020a). A sequence homology and bioinformatic approach can predict candidate targets for immune responses to SARSCoV-2. Cell Host \& Microbe, 27(4), 671-680. https://doi.org/10.1016/j.chom.2020.03.002

Grifoni, A., Weiskopf, D., Ramirez, S. I., Mateus, J., Dan, J. M., Moderbacher, C. R., ... \& Sette, A. (2020b). Targets of T cell responses to SARS-CoV2 coronavirus in humans with COVID-19 disease and unexposed individuals. Cell, 181(7), 1489-1501. https://doi.org/10.1016/j.cell.2020.05.015 
Gupta, V., Bhoyar, R. C., Jain, A., Srivastava, S., Upadhayay, R., Imran, M., ... \& Sivasubbu, S. (2020). Asymptomatic reinfection in 2 healthcare workers from India with genetically distinct severe acute respiratory syndrome Coronavirus 2. Clinical Infectious Diseases. doi.org/10.1093/cid/ciaa1451

Hung, I. F. N., Cheng, V. C. C., Li, X., Tam, A. R., Hung, D. L. L., Chiu, K. H. Y., ... \& Yuen, K. Y. (2020). SARS-CoV-2 shedding and seroconversion among passengers quarantined after disembarking a cruise ship: a case series. The Lancet Infectious Diseases, 20(9), 1051-1060. https://doi.org/10.1016/S1473-3099(20)30364-9

Ibarrondo, F. J., Fulcher, J. A., Goodman-Meza, D., Elliott, J., Hofmann, C., Hausner, M. A., ... \& Yang, O. O. (2020). Rapid decay of anti-SARSCoV-2 antibodies in persons with mild Covid-19. New England Journal of Medicine, 383(11), 1085-1087. doi.org/10.1056/NEJMc2025179

Iwasaki, A. (2021). What reinfections mean for COVID-19. The Lancet Infectious Diseases, 21(1), 3-5. doi.org/10.1016/S1473-3099(20)30783-0

Jordan, R. E., Adab, P., \& Cheng, K. (2020). Covid-19: risk factors for severe disease and death. BMJ, 368, m1198. https://doi.org/10.1136/bmj.m1198

Ju, B., Zhang, Q., Ge, J., Wang, R., Sun, J., Ge, X., ... \& Zhang, L. (2020). Human neutralizing antibodies elicited by SARS-CoV-2 infection. Nature, 584(7819), 115-119. doi.org/10.1038/s41586-020-2380-z

Le Bert, N., Tan, A. T., Kunasegaran, K., Tham, C. Y., Hafezi, M., Chia, A., ... \& Bertoletti, A. (2020). SARS-CoV-2-specific T cell immunity in cases of COVID-19 and SARS and uninfected controls. Nature, 584(7821), 457-462.

https://doi.org/10.1038/s41586-020-2550-z

Liu, L., To, K. K. W., Chan, K. H., Wong, Y. C., Zhou, R., Kwan, K. Y., ... \& Chen, Z. (2020). High neutralizing antibody titer in intensive care unit patients with COVID-19. Emerging Microbes \& Infections, 9(1), 1664-1670. https://doi.org/10.1080/22221751.2020.1791738

Long, Q. X., Tang, X. J., Shi, Q. L., Li, Q., Deng, H. J., Yuan, J., ... \& Huang, A. L. (2020). Clinical and immunological assessment of asymptomatic SARS-CoV-2 infections. Nature Medicine, 26(8), 1200-1204. doi.org/10.1038/s41591-020-0965-6

Poojary, M., Shantaraman, A., Jolly, B., \& Scaria, V. (2019). Computational protocol for assembly and analysis of SARS-nCoV-2 genomes. Research Reports, 4, e1-14. doi.org/10.9777/rr.2020.10001
Rambaut, A., Holmes, E. C., O'Toole, Á., Hill, V., McCrone, J. T., Ruis, C., ... \& Pybus, O. G. (2020). A dynamic nomenclature proposal for SARS-CoV-2 lineages to assist genomic epidemiology. Nature Microbiology, 5(11), 1403-1407. doi.org/10.1101/2020.04.17.046086

Robbiani, D. F., Gaebler, C., Muecksch, F., Lorenzi, J. C., Wang, Z., Cho, A., ... \& Nussenzweig, M. C. (2020). Convergent antibody responses to SARS-CoV-2 in convalescent individuals. Nature, 584(7821), 437-442. doi.org/10.1038/s41586-020-2456-9

Roy, S. (2020). COVID-19 reinfection: myth or truth? SN Comprehensive Clinical Medicine, 2(6), 710713. https://doi.org/10.1007/s42399-020-00335-8

Rueca, M., Bartolini, B., Gruber, C. E. M., Piralla, A., Baldanti, F., Giombini, E., ... \& Capobianchi, M. R. (2020). Compartmentalized replication of SARS-Cov-2 in upper vs. lower respiratory tract assessed by whole genome quasispecies analysis. Microorganisms, 8(9), 1302 https://doi.org/10.3390/microorganisms8091302

Snyder, T. M., Gittelman, R. M., Klinger, M., May, D. H., Osborne, E. J., Taniguchi, R., ... \& Robins, H. S. (2020). Magnitude and dynamics of the T-cell response to SARS-CoV-2 infection at both individual and population levels. MEDRXIV. doi.org/10.1101/2020.07.31.20165647

Tillett, R. L., Sevinsky, J. R., Hartley, P. D., Kerwin, H., Crawford, N., Gorzalski, A., ... \& Pandori, M. (2021). Genomic evidence for reinfection with SARS-CoV-2: A case study. The Lancet Infectious Diseases, 21(1), 52-58. doi.org/10.2139/ssrn.3680955

To, K. K. W., Chan, W. M., Ip, J. D., Chu, A. W. H., Tam, A. R., Liu, R., ... \& Yuen, K. Y. (2020a). Unique SARS-CoV-2 clusters causing a large COVID-19 outbreak in Hong Kong. Clinical Infectious Diseases: An official publication of the Infectious Diseases Society of America. doi.org/10.1093/cid/ciaa1119

To, K. K. W., Tsang, O. T. Y., Leung, W. S., Tam, A. R., Wu, T. C., Lung, D. C., ... \& Yuen, K. Y. (2020b). Temporal profiles of viral load in posterior oropharyngeal saliva samples and serum antibody responses during infection by SARSCoV-2: An observational cohort study. The Lancet Infectious Diseases, 20(5), 565-574. doi.org/10.1016/S1473-3099(20)30196-1

To, K. K. W., Hung, I. F. N., Ip, J. D., Chu, A. W. H., Chan, W. M., Tam, A. R., ... \& Yuen, K. Y. (2020c). COVID-19 re-infection by a phylogenetically distinct SARS-coronavirus-2 strain confirmed by whole genome sequencing. Clinical Infectious Diseases. doi.org/10.1093/cid/ciaa1275 
Wang, Y., Zhang, L., Sang, L., Ye, F., Ruan, S., Zhong, B. ... \& Zhao, J. (2020). Kinetics of viral load and antibody response in relation to COVID-19 severity. The Journal of Clinical Investigation, 130(10). doi.org/10.1172/JCI138759

Weisblum, Y., Schmidt, F., Zhang, F., DaSilva, J., Poston, D., Lorenzi, J. C., ... \& Bieniasz, P. D. (2020). Escape from neutralizing antibodies by SARS-CoV-2 spike protein variants. Elife, 9, e61312. doi.org/10.1101/2020.07.21.214759
Xu, Y., Li, X., Zhu, B., Liang, H., Fang, C., Gong, Y., ... \& Gong, S. (2020). Characteristics of pediatric SARS-CoV-2 infection and potential evidence for persistent fecal viral shedding. Nature Medicine, 26(4), 502-505. https://doi.org/10.1038/s41591020-0817-4 